Article

\title{
Improved Forest Biomass and Carbon Estimations Using Texture Measures from WorldView-2 Satellite Data
}

\section{Sandra Eckert}

Centre for Development and Environment, University of Bern, Hallerstrasse 10, CH-3012 Bern, Switzerland; E-Mail: sandra.eckert@cde.unibe.ch; Tel.: +41-31-631-5439; Fax: +41-31-631-8544

Received: 1 February 2012; in revised form: 15 March 2012 / Accepted: 15 March 2012 /

Published: 26 March 2012

Abstract: Accurate estimation of aboveground biomass and carbon stock has gained importance in the context of the United Nations Framework Convention on Climate Change (UNFCCC) and the Kyoto Protocol. In order to develop improved forest stratum-specific aboveground biomass and carbon estimation models for humid rainforest in northeast Madagascar, this study analyzed texture measures derived from WorldView-2 satellite data. A forest inventory was conducted to develop stratum-specific allometric equations for dry biomass. On this basis, carbon was calculated by applying a conversion factor.

After satellite data preprocessing, vegetation indices, principal components, and texture measures were calculated. The strength of their relationships with the stratum-specific plot data was analyzed using Pearson's correlation. Biomass and carbon estimation models were developed by performing stepwise multiple linear regression.

Pearson's correlation coefficients revealed that (a) texture measures correlated more with biomass and carbon than spectral parameters, and (b) correlations were stronger for degraded forest than for non-degraded forest. For degraded forest, the texture measures of Correlation, Angular Second Moment, and Contrast, derived from the red band, contributed to the best estimation model, which explained $84 \%$ of the variability in the field data (relative RMSE $=6.8 \%$ ). For non-degraded forest, the vegetation index EVI and the texture measures of Variance, Mean, and Correlation, derived from the newly introduced coastal blue band, both NIR bands, and the red band, contributed to the best model, which explained $81 \%$ of the variability in the field data (relative RMSE $=11.8 \%$ ). These results indicate that estimation of tropical rainforest biomass/carbon, based on very high resolution satellite data, can be improved by (a) developing and applying forest stratum-specific models, and (b) including textural information in addition to spectral information. 
Keywords: aboveground biomass; forest carbon; tropical rainforest; REDD; Madagascar; WorldView-2; correlation; regression analysis

\section{Introduction}

The Bali Action Plan, adopted by UNFCCC at the 13th session of its Conference of the Parties (COP-13), held in Bali in December 2007, mandates Parties to negotiate a post-2012 instrument, including possible financial incentives for forest-based climate change mitigation actions in developing countries [1]. COP-13 also adopted a decision on "Reducing emissions from deforestation in developing countries (also known as REDD): approaches to stimulate action”. In 2010, the policy and mechanisms for implementing REDD were further specified and agreed in a process of long-term collaborative action [2]. UNFCCC [3] stated that REDD should be implemented by establishing monitoring systems that use an appropriate combination of remote sensing and ground-based forest carbon inventory approaches, with a focus on estimating anthropogenic forest-related greenhouse gas (GHG) emissions by sources and removals by sinks, forest carbon stocks, and forest area changes. All estimates should be transparent, consistent, as accurate as possible, and should reduce uncertainties, as far as national capabilities and capacities permit.

Forests, particularly humid tropical forests, provide a number of benefits to society. They are extremely rich in biodiversity and provide important ecosystem services, such as food, fiber, and water regulation. In addition to its role in reducing greenhouse gas emissions, REDD provides an opportunity to value and safeguard these services [4].

Satellite data make it possible to monitor and map tropical forest deforestation and degradation and thus also allow tracing changes in forest biomass and carbon stock. With multispectral medium resolution and very high resolution (VHR) sensors so far in orbit, the achieved results were biased by limited spectral resolutions or limited geometric resolutions of the sensors. This limited the automatic distinction between different forest succession stages; consequently, the established relationships between non-stratified ground measurements and remotely sensed data were weak. Since the launch of WorldView-2 in October 2009, a satellite sensor has been in orbit that acquires data of a high spatial as well as a higher spectral resolution, compared to previously launched VHR sensors, hopefully offering the opportunity to overcome these limitations.

There are numerous approaches to estimating aboveground dry biomass (hereafter referred to as biomass) from satellite data [5]. Regression analysis is the most common modeling approach [6-8], with most studies relating vegetation indices based on red and near-infrared (NIR) wavelengths with their field measurements. However, apart from the enhanced vegetation index (EVI), which proved to be sensitive to canopy variations in the tropics, vegetation indices have achieved moderate success in tropical and subtropical regions, where biomass levels are high and forest canopy is closed, with multiple layers, and where there is a great diversity of species [7,9]. Recent promising results have been achieved using texture measurement for biomass estimation, for example by Sarker et al. [8], Fuchs et al. [10], and $\mathrm{Lu}$ [7]. It is expected that texture measures derived from higher resolution satellite data will correlate even better with field data, since they allow for a finer distinction of structural detail $[11,12]$. 
The objective of this study, therefore, was to link biomass and carbon inventory data to WorldView-2 data and to analyze their relationships and the potential of WorldView-2 data for biomass and carbon estimation for two important strata of tropical rainforest that differ substantially in stored biomass and carbon. The goal is to develop improved biomass and carbon estimation models, evaluating both spectral and textural information.

\section{Study Area}

The study area is situated in the northeast of Madagascar, $200 \mathrm{~km}$ northwest of Toamasina, in the Soanierana Ivongo District of Analanjirofo Region $\left(16^{\circ} 39^{\prime} 59^{\prime \prime} \mathrm{S} / 49^{\circ} 35^{\prime} 00^{\prime \prime} \mathrm{E}\right)$. Topographically the area is characterized by a hilly landscape. Rainfall is very abundant, occurring on average on 224 days a year, and totaling up to $3,677 \mathrm{~mm}$ annually. Humidity generally reaches $75 \%$, and the average temperature in the area is $23.7^{\circ} \mathrm{C}$. The location of the study area is illustrated in Figure 1, with a forest type classification and the location of the forest inventory plots shown in the close-up.

Figure 1. Overview and zoom map of the study area. The zoom map shows a forest classification, which was derived during an earlier study [13] from a SPOT 5 satellite image, acquired in 2009. The coverage of the WorldView-2 dataset coincides with the zoom map. The classification was not repeated based on the WorldView-2 satellite image. Additionally, as well as existing paths, the forest inventory also plots and indicates waterways and villages.

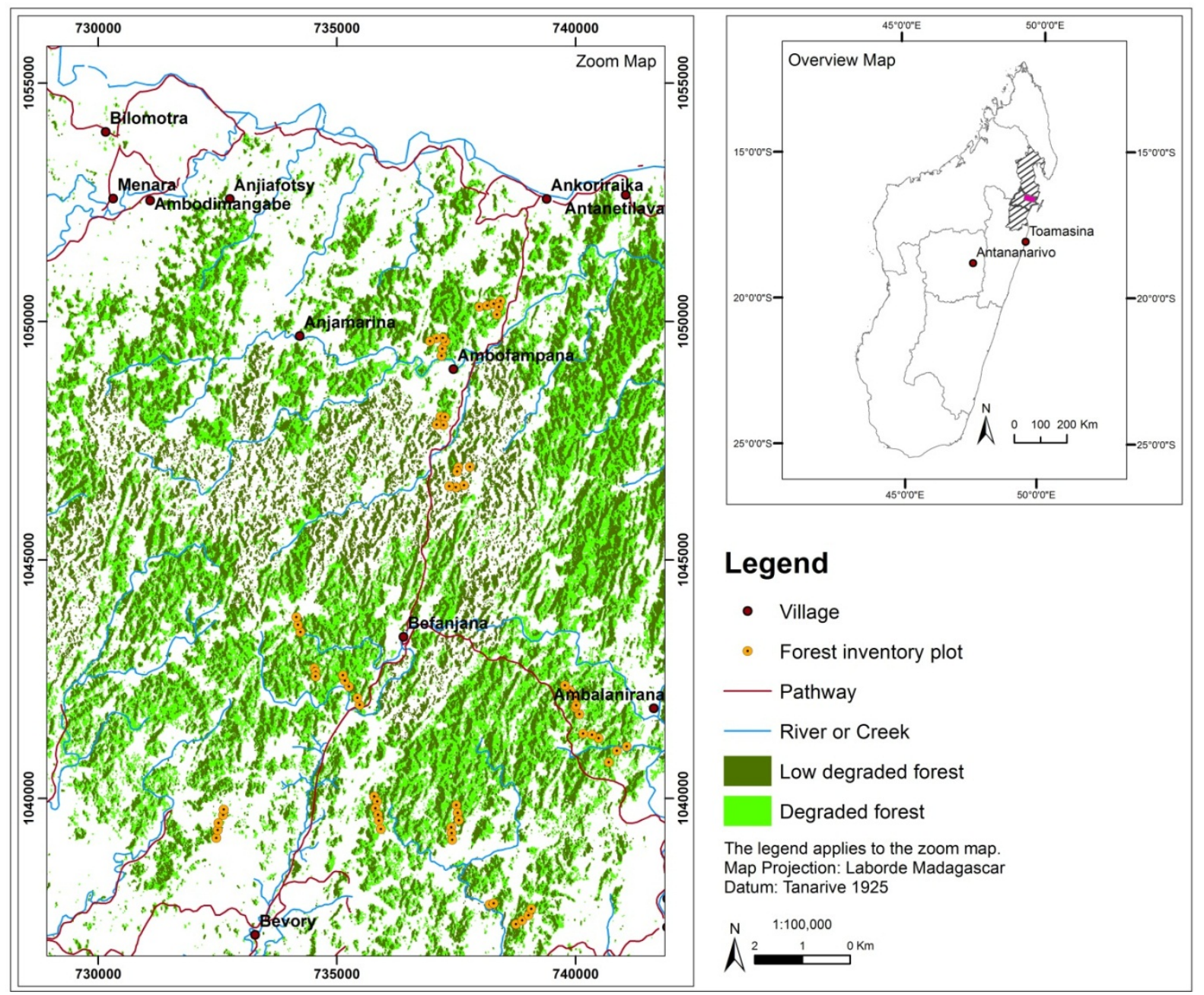


This forest area is part of an important ecological corridor situated between three protected forest areas: (a) Mananara Nord in the northeast, (b) Ambatovaky in the southwest, and (c) Pointe Larrée in the southeast.

The primary vegetation of this region is included in the "lowland rainforest" categories [14] in the Anthostema and MYRISTICACEAE class [15]. It is characterized in particular by dense evergreen trees with a canopy exceeding $30 \mathrm{~m}$ in height. The main threat to the lowland rainforest is from subsistence agriculture - through slash-and-burn activities, locally called "tavy" - and from illegal logging, which are the main causes of deforestation and degradation of the primary vegetation [16-20]. Consequently, the forests can be categorized into three forest degradation and disturbance classes as well as a fourth class consisting of other formations and non-forest as described in Table 1.

Table 1. Characterization of forest degradation types present in the lowland rainforest in the study area.

\begin{tabular}{|c|c|c|}
\hline Class & Characterization & Photo \\
\hline $\begin{array}{l}\text { Non-degraded } \\
\text { forest }\end{array}$ & $\begin{array}{l}\text { Non-degraded forest with a very low level of } \\
\text { disturbance. Contains a high carbon stock, close to a } \\
\text { climax situation. Dense and closed canopy cover } \\
\text { representing all types of typical plants (trees, palm } \\
\text { trees, ferns). }\end{array}$ & \\
\hline $\begin{array}{l}\text { Degraded } \\
\text { forest }\end{array}$ & $\begin{array}{l}\text { Degraded forest with a higher level of disturbance, } \\
\text { but still with a high diversity and quantity of plants. } \\
\text { Reduced carbon stock. Canopy cover is open. }\end{array}$ & \\
\hline $\begin{array}{l}\text { Secondary } \\
\text { formations }\end{array}$ & $\begin{array}{l}\text { Vegetation regrowth after several disturbances of } \\
\text { high intensity (generally regrowth after } \\
\text { slash-and-burn activities) }\end{array}$ & \\
\hline $\begin{array}{l}\text { Other } \\
\text { formations and } \\
\text { non-forest }\end{array}$ & $\begin{array}{l}\text { Other formations, generally very highly degraded, } \\
\text { with species such as Asplenium spp. indicating } \\
\text { extreme degradation. A condition reached after } \\
\text { frequent heavy disturbances of high intensity. }\end{array}$ & \\
\hline
\end{tabular}




\section{Materials and Methods}

\subsection{Field Data}

Field data were collected in early 2009. All plots were selected randomly for the two forest strata. Their location was measured by a handheld GPS device. GPS data were post-processed, resulting in a horizontal accuracy of $10-15 \mathrm{~m}$. In order to minimize erroneous effects on the results due to positioning errors, the $10 \mathrm{~m} \times 50 \mathrm{~m}$ plots were selected based on the criterion that the surrounding forest vegetation within at least $10 \mathrm{~m}$ distance from the plot was the same as within the plot.

Aboveground biomass data were collected and obtained by applying stratified random sampling, followed by the calculation of allometric equations based on sample extraction calculation from the field. In this way, wood density was derived from branch density extrapolation using randomized branch sampling [21,22]. Wood density and the weight of the leaves were measured after drying at $70{ }^{\circ} \mathrm{C}$ until the weight no longer changed. Biomass was calculated using the forest type (model II) developed by Chave et al. [23]. In addition, the biomass values were validated using the international equations developed by Brown [24], adapted for humid areas (1,500 $\mathrm{mm}<\mathrm{P}<4,000 \mathrm{~mm})$.

The biomass inventory was carried out for a total of 96 plots, including 48 plots of non-degraded forest and 48 plots of degraded forest. Each plot $(10 \mathrm{~m} \times 50 \mathrm{~m})$ consisted of five subplots $(10 \mathrm{~m} \times 10 \mathrm{~m})$. Each of these was subdivided into three compartments of different sizes, in which trees of different diameters were inventoried [25]. In compartment A $(10 \mathrm{~m} \times 10 \mathrm{~m})$ all trees with $d_{A}>20 \mathrm{~cm}$ were inventoried, in compartment B $(5 \mathrm{~m} \times 5 \mathrm{~m})$ all trees with $5 \mathrm{~cm}<d_{B}<20 \mathrm{~cm}$, and in compartment $\mathrm{C}(2.5 \mathrm{~m} \times 2.5 \mathrm{~m})$ all trees with $d_{C}<5 \mathrm{~cm}$. The dendrometric characteristics of each tree were recorded as: total height $h_{t}$, bole height $h_{B}$, length of the crown $l_{c}$, diameter at $1.30 \mathrm{~m}$ height $d_{1.30}$, and basal diameter for small trees $d_{b}$.

In order to generate regressions for the allometric equations, biomass samples for the two strata were collected. For this purpose, two macroplots of $100 \mathrm{~m} \times 100 \mathrm{~m}$ were randomly selected in the study area, and samples were measured within subplots of $10 \mathrm{~m} \times 10 \mathrm{~m}$ situated in each corner of each macroplot.

To ensure representativeness, 128 trees were randomly chosen in each subplot for the biomass modeling: 64 trees each for the two stratification classes (degraded forest and low-degraded forest). These trees were measured and then subdivided into four diameter size classes as follows: (1) $d_{1.30} \leq 10 \mathrm{~cm}$; (2) $10 \mathrm{~cm}<d_{1.30} \leq 20 \mathrm{~cm}$; (3) $20 \mathrm{~cm}<d_{1.30} \leq 30 \mathrm{~cm}$ ); and (4) $d_{1.30}>30 \mathrm{~cm}$. Additionally, for every tree, three biomass subpools — branch, bole, and crown — were considered for the volume calculation:

$$
\begin{gathered}
\text { - for the bole : } \quad V B=\left(\frac{\pi}{4}\right) * d_{1,30}^{2} * h_{B} \\
\text { - for the branch : } \quad V b=\left(\frac{\pi}{12}\right) * d_{b}^{2} * L_{b} \\
\text { - for the crown : } \quad V c=\left(\frac{4 \pi}{3}\right) * \frac{h c}{2} *\left[\left(L_{c}+l_{c}\right) / 4\right]^{2}
\end{gathered}
$$

where:

$\mathrm{V}_{\mathrm{B}}$ : volume of bole

$d_{1.30}$ : diameter at $1.30 \mathrm{~m}$ height (diameter at breast height, $\mathrm{DBH}$ )

$h_{B}$ : height of bole 
$V_{b}$ : volume of branch

$d_{b}$ : diameter of branch

$L_{b}$ : length of branch

$V_{c}$ : volume of crown

$h_{c}$ : height of crown

$L_{c}$ : length of crown

$l_{c}$ : width of crown [26,27].

Total biomass for each tree was calculated by summarizing all subpool volumes multiplied with their specific subpool mean density (for the bole: $0.60 \mathrm{t} / \mathrm{m}^{3}$, for the branch: $0.58 \mathrm{t} / \mathrm{m}^{3}$, and for the crown: $0.000346 \mathrm{t} / \mathrm{m}^{3}$ ). The resulting biomass values for each tree were then correlated with its measured DBH and height values in order to develop regression models with strong relationships. The highest $R^{2}$ (0.978) was obtained with the following allometric equation:

where:

$$
Y=0.0061 * d_{1.30}^{2.719}
$$

$$
\begin{aligned}
& \mathrm{Y} \text { : biomass of a tree }[\mathrm{kg}] \\
& d_{1.30} \text { : diameter at } 1.30 \mathrm{~m} \text { height }[\mathrm{cm}]
\end{aligned}
$$

This formula was used to calculate biomass. For the calculation of carbon, biomass was multiplied with a conversion factor of 0.5 , which is the default factor recommended by the International Panel on Climate Change (IPCC) [28].

The statistics of both parameters are listed in Table 2. More details on the species composition in the sample plots, the determination of biomass and carbon, and the corresponding statistical analysis can be found in Rakotondrasoa [26].

Table 2. Statistical overview of the used field plots in [t/ha].

\begin{tabular}{cccccc}
\hline Parameter \& Forest Stratum & No. & Min. & Max. & Mean & S.D. \\
\hline Biomass, non-degraded & 20 & 323.304 & 1048.085 & 575.853 & 162.757 \\
Biomass, degraded & 22 & 217.165 & 572.223 & 359.572 & 79.727 \\
Carbon, non-degraded & 20 & 161.652 & 524.043 & 287.926 & 81.378 \\
Carbon, degraded & 22 & 108.583 & 286.112 & 179.786 & 39.863 \\
\hline
\end{tabular}

Due to a partial cloud and thick haze cover in the WorldView-2 satellite data, only a reduced sample size of 42 plots was available for this study. Of these plots, 25 are situated on flat areas and gently inclined slopes up to $6^{\circ}, 14$ are on slopes between $6^{\circ}$ and $10^{\circ}$, and three are on steep slopes of around $20^{\circ}$.

\subsection{Satellite Data and Preprocessing}

The optical satellite sensor WorldView-2 was launched in October 2009. The sensor provides panchromatic data at a geometric resolution of $0.5 \mathrm{~m}$, as well as multispectral data divided into eight spectral bands at a geometric resolution of $0.2 \mathrm{~m}$. The spectral ranges of the eight bands are $0.40-0.45 \mu \mathrm{m}$ (band 1-coastal blue), 0.45-0.51 $\mu \mathrm{m}$ (band 2-blue), 0.51-0.58 $\mu \mathrm{m}$ (band 3-green), 0.585-0.625 $\mu \mathrm{m}$ 
(band 4-yellow), 0.63-0.69 $\mu \mathrm{m}$ (band 5-red), 0.705-0.745 $\mu \mathrm{m}$ (band 6-red edge), 0.77-0.895 $\mu \mathrm{m}$ (band 7-near-infrared1), and 0.86-1.04 $\mu \mathrm{m}$ (band 8-near-infrared2).

The satellite data were delivered in product level LV3D, meaning that the data had been sensor-corrected, radiometrically corrected, and orthorectified. It was acquired with a mean in-track and cross-track viewing angle of $7.3^{\circ}$ and $17.1^{\circ}$ respectively, and a sun azimuth and sun elevation angle of $111.1^{\circ}$ and $66.8^{\circ}$.

According to DigitalGlobe [29], the geolocation accuracy of the delivered image data ranges from $4.6 \mathrm{~m}$ to $10.7 \mathrm{~m}$ (CE90). This was checked by comparing the data to a georeferenced SPOT 5 dataset with a geometric resolution and accuracy of $5 \mathrm{~m}$. The two datasets are in good agreement. Consequently, the horizontal accuracy of the WorldView-2 dataset is about $5 \mathrm{~m}-10 \mathrm{~m}$.

Digital numbers were converted to top-of-atmosphere reflectance using the absolute radiometric calibration factors and effective bandwidths for each band, according to the formulas and directions provided by the satellite data provider DigitalGlobe [30]. The WorldView-2 data were then atmospherically corrected in order to reduce haze as well as other atmospheric and solar illumination influences. This was done using ATCOR 2, a procedure developed by Richter [31], which is capable of handling horizontally varying optical depths and contains a statistical haze removal algorithm. A radiative transfer code is required to compute the atmospheric transmittance, direct and diffuse solar flux, and path radiance. These quantities are summarized as atmospheric correction functions and had been previously calculated using the MODTRAN 4 code for several sensors, including WorldView- 2 .

Topographic correction was tested with the only available digital surface model (DSM) for the area, the Shuttle Radar Topography Mission (SRTM) DSM. It has a horizontal resolution of $90 \mathrm{~m}$, which is insufficient for correcting topography of a WorldView-2 dataset with a horizontal resolution of $2 \mathrm{~m}$. Nevertheless, the SRTM DSM was re-sampled step by step from $90 \mathrm{~m}$ to $45 \mathrm{~m}$, from $45 \mathrm{~m}$ to $30 \mathrm{~m}$, from $30 \mathrm{~m}$ to $15 \mathrm{~m}$, from $15 \mathrm{~m}$ to $5 \mathrm{~m}$, and from $5 \mathrm{~m}$ to the required resolution of $2 \mathrm{~m}$. Besides the coarse resolution, a slight positional shift between the SRTM DSM and the WorldView-2 dataset was observed. After topographic correction, the consequences of this shift, combined with the coarse resolution, led to a chessboard pattern as well as a slightly shifted correction near ridges and summits. Differences between topographically corrected and uncorrected single band and vegetation index values for each plot were analyzed but proved to be very small. For this reason, it was decided to neglect topographic correction in order not to introduce an additional error to the reflectance values.

\subsection{Simple Reflectance, Vegetation Indices, and Grey-level Co-occurrence (GLCM) Texture Measures}

Preprocessing of a set of band ratios was followed by the calculation of vegetation indices, texture measures, and principal components. They were selected, based on previous research dealing with biomass and carbon estimations from optical satellite data [8,10,32,33]. GLCM texture measures were calculated for five different window sizes ranging from $15 \times 15$ to $23 \times 23$ pixels. The window sizes were determined after initial correlation tests on a small subset area. Considering the pixel size of $2.0 \mathrm{~m}$, average window sizes were selected. In this way, shadow structures caused by trees are retained; ideally, these shadow structures differ between the two forest strata due to their specific characteristics, as described in Table 1. 
WorldView-2 provides two bands in the near-infrared range of the electromagnetic spectrum: bands 7 and 8. Vegetation indices and ratios were calculated using each of the two near-infrared bands. For example, NDVI1 refers to NDVI, calculated using band 7 (NIR1), and NDVI2 refers to NDVI, calculated using band 8 (NIR2).

The mean value of all calculated parameters based on WorldView-2 data was derived for each of the 42 plots sized $10 \mathrm{~m} \times 50 \mathrm{~m}$. All derived parameters that were related to the field plot data are listed in Table 3.

Table 3. Selected spectral parameters and GLCM texture measures.

\begin{tabular}{|c|c|c|}
\hline Parameter & Formula & References \\
\hline \multicolumn{3}{|l|}{ Single bands } \\
\hline \multicolumn{3}{|l|}{ WorldView- 2 bands $1-8$} \\
\hline \multicolumn{3}{|l|}{ Vegetation indices } \\
\hline ARVI & $(\mathrm{NIR}-2 \times \mathrm{RED}+\mathrm{BLUE}) /(\mathrm{NIR}+2 \times \mathrm{RED}-\mathrm{BLUE})$ & [34] \\
\hline EVI & $\mathrm{G} \times((\mathrm{NIR}-\mathrm{RED}) /(\mathrm{NIR}+\mathrm{C} 1 \times \mathrm{RED}-\mathrm{C} 2 \times \mathrm{xBUE}+\mathrm{L}))$ & [35] \\
\hline IPVI & $\mathrm{NIR} /(\mathrm{NIR}+\mathrm{RED})$ & [36] \\
\hline NDVI & $(\mathrm{NIR}-\mathrm{RED}) /(\mathrm{NIR}+\mathrm{RED})$ & [37] \\
\hline OSAVI & $(\mathrm{NIR}-\mathrm{RED}) /(\mathrm{NIR}+\mathrm{RED}+\mathrm{Y})$ & [38] \\
\hline \multicolumn{3}{|l|}{ Image transform } \\
\hline \multicolumn{2}{|l|}{ Principal components $1-8$} & [39] \\
\hline \multicolumn{3}{|l|}{ Simple ratios } \\
\hline RVI & NIR/RED & [40] \\
\hline NIR/GREEN & NIR/GREEN & \\
\hline GRVI & GREEN/RED & [41] \\
\hline \multicolumn{3}{|c|}{ GLCM texture measures (window sizes: $15 \times 15-23 \times 23$ pixels) } \\
\hline & & [42] \\
\hline \multicolumn{3}{|l|}{ Mean } \\
\hline \multicolumn{3}{|l|}{ Variance } \\
\hline \multicolumn{3}{|l|}{ Homogeneity } \\
\hline \multicolumn{3}{|l|}{ Contrast } \\
\hline \multicolumn{3}{|l|}{ Dissimilarity } \\
\hline \multicolumn{3}{|l|}{ Entropy } \\
\hline \multicolumn{3}{|l|}{ Angular Second Moment } \\
\hline Correlation & & \\
\hline
\end{tabular}

ARVI: atmospherically resistant vegetation index; EVI: enhanced vegetation index, with $\mathrm{G}=2.5, \mathrm{C} 1=6, \mathrm{C} 2=$ 7.5, L = 1; IPVI: infrared percentage vegetation index; NDVI: normalized difference vegetation index; OSAVI: optimized soil-adjusted vegetation index, with $\mathrm{Y}=0.16$; RVI: ratio vegetation index; GRVI: green ratio vegetation index; NIR: near-infrared; NIR1: band 7; NIR2: band 8; BLUE: visible blue band; RED: visible red band; GREEN: visible green band.

\subsection{Statistical Analysis}

The relationships between biomass, carbon, and the computed mean value of each parameter per plot were analyzed using Pearson's correlation, as well as stepwise multiple linear regression. The 
analysis included the available 20 plots representing the non-degraded forest stratum and 22 plots representing the degraded forest stratum. Bootstrap sampling was performed in order to account for the rather small sample sizes (see Tables A1-A8 of supplementary). The statistical parameters: $R^{2}$, adjusted $R^{2}$, p-level for the model, and root mean square error (RMSE) were calculated to ensure that the analysis would yield the best-fitting models for the two forest strata. Multicollinearity and overfitting indicators, Tolerance and Variance Inflation Factor (VIF), were taken into account as well.

\section{Results}

Since carbon was derived from the biomass data by multiplying it by a conversion factor of 0.5 , all subsequent correlation and $R^{2}$ results apply to both biomass and carbon.

\subsection{Relationships between Biomass/Carbon and Parameters Derived from WorldView-2 Data}

For the non-degraded forest stratum, Pearson's correlation between biomass/carbon and parameters derived from WorldView-2 data resulted in one parameter with a significant coefficient: EVI2, with $R^{2}=0.413(p=0.01)$. Moderate correlations $(p=0.05)$ resulted for EVI1, band 6 (red edge), band 7 (NIR1), and band 8 (NIR2), as well as PC1 and PC2, and the textural measure Correlation of band 2 (blue) with a window size of $23 \times 23$ pixels.

For the degraded forest stratum, several texture measures correlated significantly: Correlation of band 5 (red), Mean of band 3 (green), Mean of band 4 (yellow), and particularly Mean of band 6 (red edge), Mean of band 7 (NIR1), and Mean of band 8 (NIR2). The smallest selected window size of $15 \times 15$ pixels achieved highest correlation coefficients, and correlations weakened with increasing window sizes. Pearson's correlation coefficients between biomass/carbon and the spectral and textural parameters are listed in Table 4.

Table 4. Statistically significant Pearson's correlation coefficients $r$ and $R^{2}$ for linear relationships between carbon/biomass and the derived spectral parameters from the WorldView-2 data as well as between carbon/biomass and the textural parameters. Spectral parameters are listed in the order of decreasing correlations; textural parameters are listed in the order of increasing window sizes.

\begin{tabular}{clll}
\hline Stratum & Parameter & Pearson's r & $\boldsymbol{R}^{2}$ \\
\hline Non-degraded forest (n=20) & EVI 2 & $0.643^{* *}$ & 0.413 \\
& EVI 1 & $0.531^{*}$ & 0.282 \\
& PC 2 & $0.508^{*}$ & 0.258 \\
& Band 8 & $0.499^{*}$ & 0.249 \\
& Band 7 & $0.486^{*}$ & 0.236 \\
& Band 6 & $0.480^{*}$ & 0.230 \\
& PC 1 & $0.453^{*}$ & 0.205 \\
& GLCM23 Correlation band 2 & $0.454^{*}$ & 0.206 \\
\hline
\end{tabular}


Table 4. Cont.

\begin{tabular}{|c|c|c|c|}
\hline \multirow[t]{30}{*}{ Degraded forest $(\mathrm{n}=22)$} & GLCM15 Correlation band 5 & $0.766^{* *}$ & 0.587 \\
\hline & GLCM15 Mean band 6 & $0.758^{* *}$ & 0.575 \\
\hline & GLCM15 Mean band 8 & $0.723^{* *}$ & 0.523 \\
\hline & GLCM15 Mean band 7 & $0.719^{* *}$ & 0.517 \\
\hline & GLCM15 Mean band 4 & $0.614^{* *}$ & 0.377 \\
\hline & GLCM15 Mean band 3 & $0.604^{* *}$ & 0.365 \\
\hline & GLCM17 Correlation band 5 & $0.718^{* *}$ & 0.516 \\
\hline & GLCM17 Mean band 6 & $0.754^{* *}$ & 0.569 \\
\hline & GLCM17 Mean band 8 & $0.718^{* *}$ & 0.516 \\
\hline & GLCM17 Mean band 7 & $0.714^{* *}$ & 0.510 \\
\hline & GLCM17 Mean band 4 & $0.611^{* *}$ & 0.373 \\
\hline & GLCM17 Mean band 3 & $0.601^{* *}$ & 0.361 \\
\hline & GLCM19 Correlation band 5 & $0.637^{* *}$ & 0.406 \\
\hline & GLCM19 Mean band 6 & $0.750^{* *}$ & 0.563 \\
\hline & GLCM19 Mean band 8 & $0.713^{* *}$ & 0.508 \\
\hline & GLCM19 Mean band 7 & $0.709^{* *}$ & 0.503 \\
\hline & GLCM19 Mean band 4 & $0.608^{* *}$ & 0.370 \\
\hline & GLCM19 Mean band 3 & $0.598^{* *}$ & 0.358 \\
\hline & GLCM21 Correlation band 5 & $0.637^{* *}$ & 0.406 \\
\hline & GLCM21 Mean band 6 & $0.750^{* *}$ & 0.563 \\
\hline & GLCM21 Mean Band 8 & $0.713^{* *}$ & 0.508 \\
\hline & GLCM21 Mean band 7 & $0.709^{* *}$ & 0.503 \\
\hline & GLCM21 Mean band 4 & $0.608^{* *}$ & 0.370 \\
\hline & GLCM21 Mean band 3 & $0.598^{* *}$ & 0.358 \\
\hline & GLCM23 Correlation band 5 & $0.543^{* *}$ & 0.295 \\
\hline & GLCM23 Mean band 6 & $0.746^{* *}$ & 0.557 \\
\hline & GLCM23 Mean band 8 & $0.709^{* *}$ & 0.503 \\
\hline & GLCM23 Mean band 7 & $0.705^{* *}$ & 0.497 \\
\hline & GLCM23 Mean band 4 & $0.606^{* *}$ & 0.367 \\
\hline & GLCM23 Mean band 3 & $0.596^{* *}$ & 0.355 \\
\hline
\end{tabular}

** Correlation is significant at the 0.01 level. * Correlation is significant at the 0.05 level.

\subsection{Stepwise Multiple Linear Regression Modeling}

Stepwise multiple linear regression models were calculated using biomass and carbon as the dependent variables and all other parameters as the independent variables. The models that fulfill the collinearity requirements with a Tolerance value of $>0.1$ and a VIF value for all variables $<10$ [8] are presented in Tables 5 and 6 . 
Table 5. Generated models and statistics for biomass and carbon in "non-degraded forest".

\begin{tabular}{|c|c|c|c|c|c|c|c|}
\hline $\begin{array}{l}\text { Model (non-degraded } \\
\text { forest) (bootstrapping No. } \\
\text { of samples) } \\
\text { Variables }\end{array}$ & $R^{2}$ & Adj. $R^{2}$ & $\begin{array}{c}\text { RMSE } \\
\text { [t/ha] } \\
\text { (Biomass) }\end{array}$ & $\begin{array}{c}\text { RMSE } \\
\text { [t/ha] } \\
\text { (Carbon) }\end{array}$ & $\begin{array}{c}\text { Relative RMSE } \\
\text { [\%] } \\
\text { (Carbon/Biomass) }\end{array}$ & $\begin{array}{c}\text { Tolerance } \\
(>0.1)\end{array}$ & $\begin{array}{l}\text { VIF } \\
(<10)\end{array}$ \\
\hline $1(\mathrm{n}=30)$ & 0.413 & 0.381 & 128.08 & 64.04 & 21.74 & & \\
\hline EVI2 & & & & & & 1.000 & 1.000 \\
\hline $2(n=60)$ & 0.639 & 0.596 & 103.40 & 51.70 & $\mathbf{1 7 . 5 5}$ & & \\
\hline EVI2 & & & & & & 0.830 & 1.204 \\
\hline GLCM23 Variance band 7 & & & & & & 0.830 & 1.204 \\
\hline $3(n=100)$ & 0.746 & 0.699 & 89.30 & 44.65 & 15.16 & & \\
\hline EVI2 & & & & & & 0.826 & 1.210 \\
\hline GLCM23 Variance band 7 & & & & & & 0.824 & 1.213 \\
\hline GLCM21 Variance band 1 & & & & & & 0.980 & 1.021 \\
\hline $4(n=150)$ & 0.812 & 0.762 & 79.41 & 39.71 & 13.48 & & \\
\hline EVI2 & & & & & & 0.826 & 1.211 \\
\hline GLCM23 Variance band 7 & & & & & & 0.804 & 1.244 \\
\hline GLCM21 Variance band 1 & & & & & & 0.971 & 1.030 \\
\hline GLCM23 Mean band 8 & & & & & & 0.962 & 1.039 \\
\hline $5(n=210)$ & 0.865 & 0.816 & 69.77 & 34.89 & 11.84 & & \\
\hline EVI2 & & & & & & 0.730 & 1.370 \\
\hline GLCM23 Variance band 7 & & & & & & 0.742 & 1.349 \\
\hline GLCM21 Variance band 1 & & & & & & 0.970 & 1.031 \\
\hline GLCM23 Mean band 8 & & & & & & 0.782 & 1.279 \\
\hline GLCM23 Correlation band 5 & & & & & & 0.597 & 1.675 \\
\hline
\end{tabular}

For the non-degraded forest stratum, five models fulfill the statistical collinearity requirements. Using the most strongly correlating parameter, the vegetation index EVI2, a model was developed that explains $38 \%$ of the variability of measured biomass and carbon. It achieves a relative RMSE of $21.7 \%$ for both biomass and carbon, which corresponds to an absolute RMSE of $128 \mathrm{t} / \mathrm{ha}$ for biomass and $64 \mathrm{t} / \mathrm{ha}$ of carbon. The inclusion of four additional textural parameters led to an increase in the adjusted $R^{2}$ to 0.816 . In particular, the texture measures Variance of band 7 (NIR1), Variance of band 1 (coastal blue), Mean of band 8 (NIR2), and Correlation of band 5 (red), all with large window sizes of $21 \times 21$ as well as $23 \times 23$ pixels, led to a continuous improvement of the models. The absolute RMSE was reduced to $70 \mathrm{t} / \mathrm{ha}$ for biomass and $35 \mathrm{t} /$ ha for carbon. This corresponds to a relative RMSE of $11.8 \%$.

Three models were developed for the degraded forest stratum. They are based on the three texture measures: Correlation, Angular Second Moment, and Contrast, all derived from band 5 (red). The model using only one parameter, Correlation, achieved a relative RMSE of $11.3 \%$ for both biomass and carbon, which corresponds to an absolute RMSE of $52 \mathrm{t} / \mathrm{ha}$ for biomass and $26 \mathrm{t} / \mathrm{ha}$ of carbon. Up to $84.3 \%$ of the field data variability can be explained with a model including two additional variables, Angular Second Moment and Contrast, resulting in a absolute RMSE of $32 \mathrm{t} / \mathrm{ha}$ for biomass and an absolute RMSE of 16 t/ha for carbon. This corresponds to a relative RMSE of $6.8 \%$. Looking at the window sizes of the texture measures, the strongest correlation was found for the smallest window size 
of $15 \times 15$ pixels. Parameters with larger window sizes of $21 \times 21$ and $23 \times 23$ pixels were also selected for the best-fitting models.

The 1:1 relationships between observed and modeled biomass values for the two strata and all developed models fulfilling the statistical requirements are illustrated in Figures 2 and 3.

Table 6. Generated models and statistics for biomass and carbon in "degraded forest".

\begin{tabular}{|c|c|c|c|c|c|c|c|}
\hline $\begin{array}{l}\text { Model (degraded forest) (bootstrapping } \\
\text { no of samples) } \\
\text { Variables }\end{array}$ & $R^{2}$ & $\begin{array}{l}\text { Adj. } \\
R^{2}\end{array}$ & $\begin{array}{c}\text { RMSE } \\
\text { [t/ha] } \\
\text { (Biomass) }\end{array}$ & $\begin{array}{c}\text { RMSE } \\
\text { [t/ha] } \\
\text { (Carbon) }\end{array}$ & $\begin{array}{c}\text { Relative } \\
\text { RMSE } \\
\text { [\%] }\end{array}$ & $\begin{array}{l}\text { Tolerance } \\
(>0.1)\end{array}$ & $\operatorname{VIF}(<10)$ \\
\hline $\begin{array}{l}1(\mathrm{n}=30) \\
\text { GLCM15 Correlation band } 5\end{array}$ & 0.587 & 0.567 & 52.49 & 26.24 & 11.33 & 1.000 & 1.000 \\
\hline $\begin{array}{l}2(\mathrm{n}=60) \\
\text { GLCM15 Correlation band } 5 \\
\text { GLCM21 Angular Second Moment band } 5\end{array}$ & 0.816 & 0.796 & 36.00 & 18.00 & 7.77 & $\begin{array}{l}0.598 \\
0.598\end{array}$ & $\begin{array}{l}1.673 \\
1.673\end{array}$ \\
\hline $\begin{array}{l}3(\mathrm{n}=100) \\
\text { GLCM15 Correlation band } 5 \\
\text { GLCM21 Angular Second Moment band } 5 \\
\text { GLCM23 Contrast band } 5\end{array}$ & 0.865 & 0.843 & 31.60 & 15.80 & 6.82 & $\begin{array}{l}0.594 \\
0.596 \\
0.994\end{array}$ & $\begin{array}{l}1.683 \\
1.676 \\
1.006\end{array}$ \\
\hline
\end{tabular}

Figure 2. Measured biomass vs. modeled biomass for non-degraded forest. Models 1-5 (a-e) were plotted indicating adjusted $R^{2}$ and absolute RMSE. Each circle corresponds to a measurement plot. The diagonal represents the 1:1 relationship.

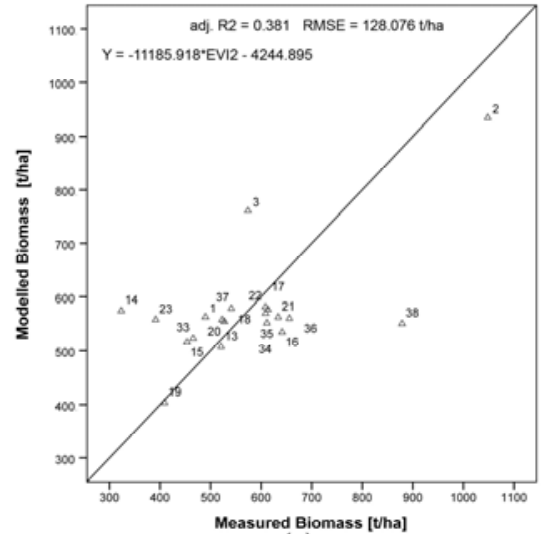

(a)

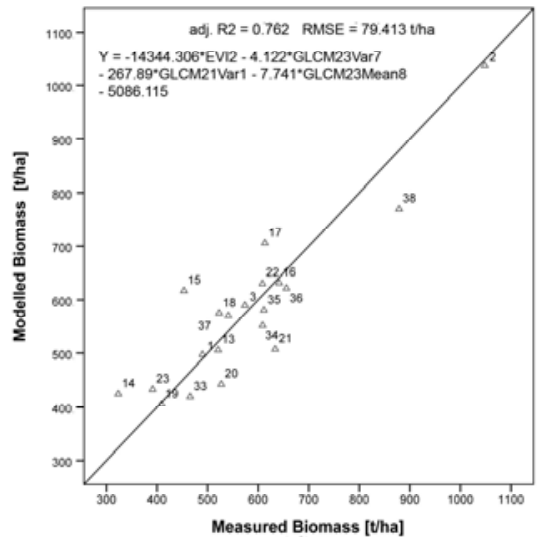

(d)

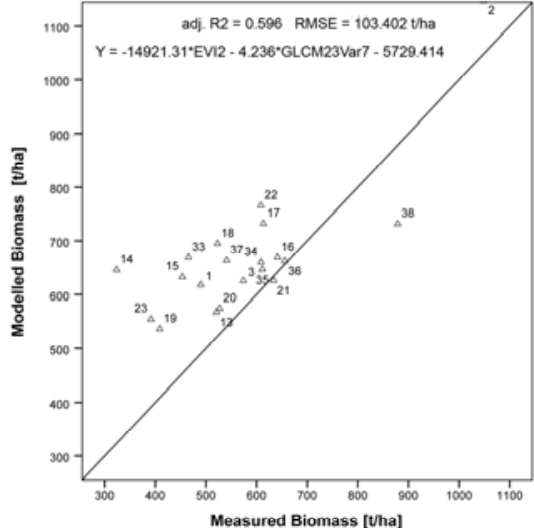

(b)

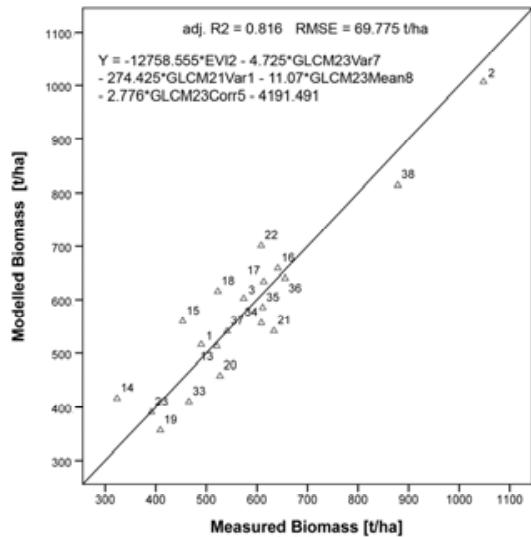

(e)

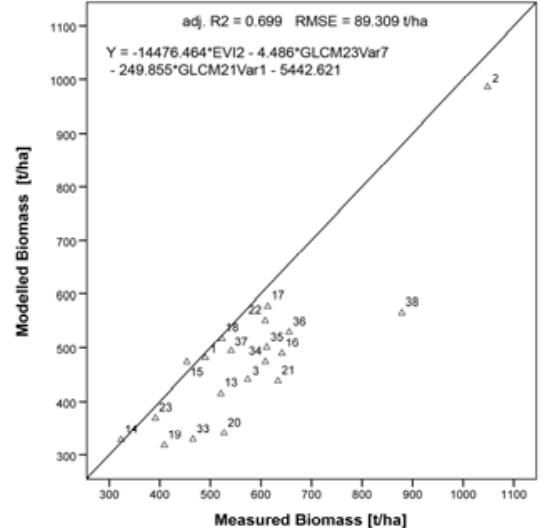

(c) 
Figure 2 shows the relationships between the modeled and the observed biomass values for the non-degraded forest stratum. The simple linear model based on EVI modeling non-degraded forest biomass (Model 1) yielded moderate results, overestimating the two lowest biomass values (plots 14 and 23). The middle-range biomass values were well-modeled, with moderate errors. The highest two biomass values were both underestimated (plots 2 and 38). With Model 2, adding the GLCM texture measure Variance of band 7 (NIR1), most plots tended to be overestimated, but with less outliers. Model 3, which included the additional GLCM texture measure Variance of band 1 (coastal blue), tended to underestimate biomass, but with a decreasing error. With Model 4 and Model 5, over- and under-estimations were balanced for plots with low and high biomass values.

Figure 3. Measured biomass vs. modeled biomass for degraded forest. Models 1-3 (a-c) were plotted indicating adjusted $R^{2}$ and absolute RMSE. Each circle corresponds to a measurement plot. The diagonal represents the 1:1 relationship.

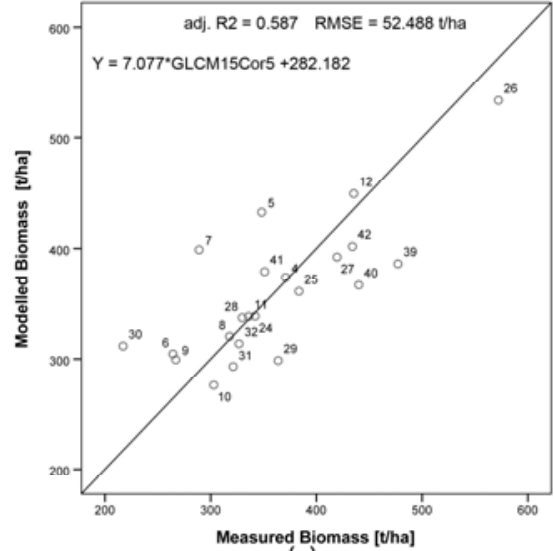

(a)

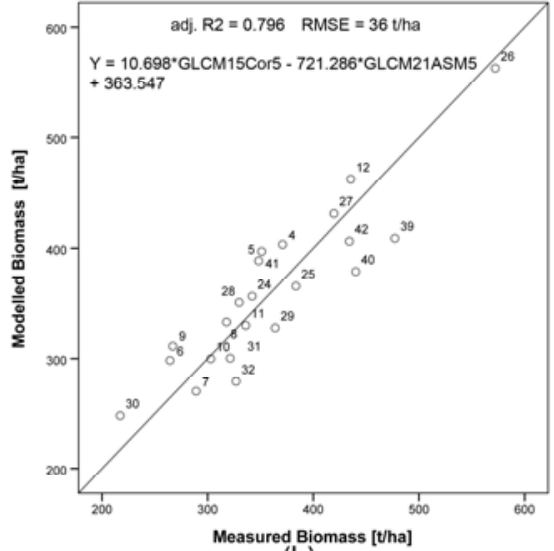

(b)

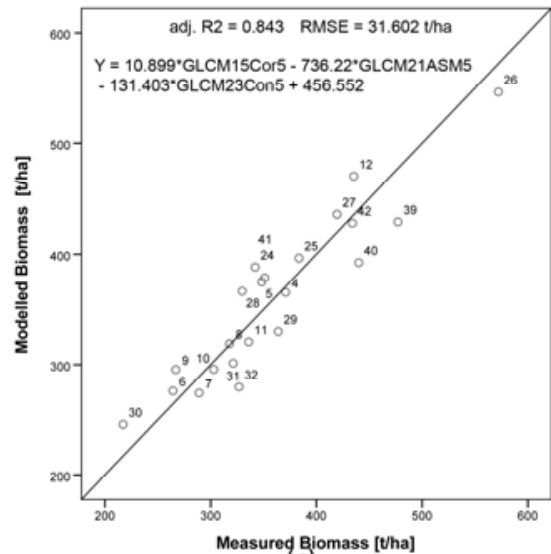

(c)

Figure 3 shows the relationship between the modeled and the measured biomass values for degraded forest. Model 1 based on the GLCM texture measure Correlation of band 5 (red) led to a well-balanced model with only few plots for which biomass was overestimated (plots 30, 7, 5) or underestimated (plots 40, 39 and 29). The GLCM texture measures Angular Second Moment and Contrast — both, again, derived from band 5 (red) - led to further improvements in Model 2 and Model 3, respectively.

\section{Discussion}

The objective of this study was to link biomass and carbon inventory data to WorldView-2 data and to analyze their relationships and the potential of WorldView-2 data for improved biomass and carbon estimation for two important strata of tropical rainforest. Models based on spectral and textural information were developed to estimate dry biomass and carbon. Pearson's correlation revealed that (a) texture measures correlate more with biomass and carbon than spectral parameters, and (b) correlations are stronger for degraded forest than for non-degraded forest. The relative RMSE of the best models developed for each forest stratum are low, compared to results of other studies, and are thus promising. 
Nevertheless, some critical points need to be addressed. The sample size of this study was limited, which is critical, but occurs frequently in the development of remote sensing-based biomass estimation models [5], particularly for areas that are difficult to access. The humid lowland rainforest with its dense vegetation is difficult to cross, which makes data collection extremely costly in terms of labor, time, and financial means. Unfortunately, the cloud cover in the satellite data further reduced the amount of usable samples in this study. Nevertheless, 42 sample plots were successfully linked to the satellite data, and the established relationships can serve as valuable information for future research on relating forest inventory data for humid rainforest to satellite data.

Linking field data to satellite data requires accurate preprocessing of all datasets. The positional error of the forest inventory plots and the satellite data must be minimal to ensure correspondence. During field work, the horizontal positioning error caused by the GPS when delineating field plots was kept within 10-15 m. The horizontal accuracy of the WorldView-2 data is within 5-10 m, according to DigitalGlobe [29]. In order to prevent errors caused by added positional errors of both datasets, only homogeneous forest areas of about $20 \mathrm{~m} \times 60 \mathrm{~m}$ were considered for the establishment of the $10 \mathrm{~m} \times 50 \mathrm{~m}$ plots.

Another critical point is the topographic and atmospheric correction of the dataset. An atmospheric correction was applied to reduce the influences of haze and illumination. However, the influence of slope and aspect due to changing topography might additionally affect vegetation reflectance. Almost two-thirds of the plots in the study area are on flat or slightly inclined slopes, whereas one third of the plots are on inclined or steep slopes, facing all directions. In a preliminary test, the WorldView-2 dataset was topographically corrected with the only available DSM, despite its coarse resolution of $90 \mathrm{~m}$. The correlation of pre- and post-corrected data revealed only small differences for the spectral parameters. On this basis, it was decided to perform the analysis using the topographically uncorrected satellite data.

Sun and sensor position at time of acquisition also has an influence on cast shadow and thus on image texture, and it may be argued that the relation between textural parameters and biomass might decrease if cast shadows are minimal due to specific viewing and illumination geometries. This should be considered before ordering satellite data. Further research is needed to understand the impact of changing viewing and illumination geometry on the analyzed relationships and forest types.

Overall, a stronger relationship was observed for the degraded forest stratum. The two forest strata vary in their complexity in terms of vertical distribution of live and dead biomass, leading to different amounts and distributions of cast shadow. This affects the texture and reflectance response of the satellite data [32]. Texture measures seem to capture the varying forest canopy structures of the two observed forest strata much better than spectral reflectance or band ratios, due to their sensitivity to the spatial aspects of canopy shadow. The more heterogeneous the forest canopy structure, the stronger the correlation with textural parameters. This is not only confirmed by the results of this study dealing with very high resolution satellite data, but was also observed by Sarker et al. [8] and Lu [7] when analyzing high resolution ALOS data and medium resolution Landsat TM data, respectively. Furthermore, vegetation indices often saturate in high-biomass areas $[7,43]$ due to high reflectance, and they do not always correlate strongly with biomass and carbon.

It was also observed that if biomass of a specific forest stratum correlates with forest canopy structure, it also correlates strongly with spectral parameters. Conversely, if biomass does not correlate with forest canopy structure, its relationship with texture measures is stronger than with spectral 
parameters. This was also noted by Fuchs et al. [10] for Siberian tundra forest, by Leboeuf et al. [44] for boreal black spruce stands, and by Lu et al. [32] for mature moist forest and liana forest stands in the Brazilian Amazon basin. Consequently, in the case of Malagasy lowland rainforest, the relationship between biomass and forest canopy structure is stronger for degraded forest stands than for non-degraded forest stands.

The only vegetation index that had a strong relationship with biomass and carbon was EVI for non-degraded forest. This index was developed in particular to increase sensitivity to high-biomass regions [35]. The two first principal components, as well as band 6 (red edge), band 7 (NIR1), and band 8 (NIR2), correlated moderately with biomass and carbon for non-degraded forest stands. Although textural parameters did not correlate significantly with biomass and carbon, a variety of texture measures contributed to the estimation models developed in this study: Variance, Mean, and Correlation, derived from the newly-introduced coastal blue band 1, band 7 (NIR1), band 8 (NIR2), and band 5 (red).

For the degraded forest stratum, the texture measures Mean derived from band 3 (green), band 4 (yellow), band 6 (red edge), and bands 7 and 8 (both NIR bands), as well as Correlation derived from band 5 (red) indicate a strong relationship with biomass and carbon. Besides Correlation, Angular Second Moment and Contrast, both derived from band 5, also helped to improve the models.

Unfortunately, WorldView-2 does not acquire information in the middle-infrared (MIR) wavelength range of the electromagnetic spectrum as it is acquired by the Landsat satellite sensors TM, ETM+, ASTER, or SPOT5. Several studies concluded that the relationship between the MIR wavelength range and vegetation properties, including biomass, is even stronger than for the NIR region $[32,33,45,46]$.

The relative RMSE of the models developed for both strata in this study are mostly smaller than the relative error results obtained in other studies on biomass estimation using optical satellite data under comparable conditions, in terms of forest types, biomass ranges, satellite data resolution, input parameters, validation data, and applied methodologies. Castillo-Santiago et al. [47] estimated biomass of tropical rainforest in Mexico using a combination of spectral and textural parameters derived from SPOT5 data with a spatial resolution of $10 \mathrm{~m}$ and multiple linear regression modeling, obtaining a relative RMSE of $21.2 \%$. Sarker et al. [8] achieved an RMSE of $46.5 \mathrm{t} / \mathrm{ha}$ for tropical forest biomass in Hong Kong using only textural parameters derived from ALOS data, again with a spatial resolution of $10 \mathrm{~m}$. Unfortunately, this study gives no information regarding the relative RMSE. Nonetheless, the RMSE obtained in Hong Kong is similar to that obtained in our study for the degraded forest stratum, which has comparable field plot biomass ranges.

For carbon, the absolute RMSE for the non-degraded forest stratum is similar to the absolute RMSE results obtained in a study by Foster et al. [48], with absolute RMSE of 59.1 t/ha and $74.4 \mathrm{t} / \mathrm{ha}$ for two test areas in Amazon rainforest in Bolivia, which were derived from hyperspectral Hyperion data with a spatial resolution of $30 \mathrm{~m}$. Again, no relative RMSE values are given.

These first results on linking biomass and carbon inventory data for tropical humid rainforest with very high resolution WorldView-2 satellite data are promising. The inclusion of grey level co-occurrence texture measures, as well as the subdivision of the plots into successional strata, led to a reduction of relative RMSE and to an improvement in biomass and carbon estimation models for Malagasy lowland rainforest. 
The results confirm that EVI is particularly suitable for applications designed for mapping and monitoring tropical rainforest. Furthermore, the red edge and the two near-infrared spectral bands proved to have the strongest direct relationships with the field data. Out of the generated texture measures, Angular Second Moment, Contrast, Correlation, Mean, and Variance performed well.

\section{Conclusions}

This study explored the potential of WorldView-2 data for biomass and carbon estimation of tropical humid rainforest. Pearson's correlation and stepwise multiple linear regression were performed, and models based on spectral and textural information derived from the WorldView- 2 dataset were developed. The following conclusions can be drawn:

- Texture measures seem to capture the varying forest canopy structures of the two observed forest strata much better than spectral reflectance or band ratios, except for the vegetation index EVI, which had a strong relationship with the biomass and carbon field data for non-degraded forest.

- A strong relationship was observed between the degraded forest stratum field data and the satellite data. The developed models consist of the texture measures: Correlation, Angular Second Moment, and Contrast, all derived from band 5. The best model for degraded forest achieves an adjusted $\mathrm{R}^{2}$ of 0.843 and a relative RMSE of $6.8 \%$ for biomass and carbon. Furthermore, the texture measures Mean derived from band 3 (green), band 4 (yellow), band 6 (red edge), and bands 7 and 8 (both NIR bands) indicate a strong relationship with biomass and carbon. The best model developed for degraded forest $Y_{\text {deg }}$ can be written as follows:

$$
Y \text { deg }=10.899 * \text { GLCM15Cor } 5-736.22 * \text { GLCM21ASM5 }-131.403 * \text { GLCM23Con } 5+456.5521
$$

- A slightly weaker relationship was observed between non-degraded forest stratum field data and the satellite data. EVI, using the second NIR band of the sensor, as well as Variance, Mean, and Correlation, derived from the newly-introduced coastal blue band, both NIR bands, and the red band, contributed to the best model (adjusted $\mathrm{R}^{2}=0.816$, relative $\mathrm{RMSE}=11.8 \%$ ). The best model developed for non-degraded forest $Y_{\text {low }}$ can be written as follows:

$$
\begin{gathered}
\text { Ylow }-12758.555 * \text { EVI } 2-4.725 * \text { GLCM } 23 \text { Var } 7-274.425 * \text { GLCM } 21 \text { Var } 1-11.07 \\
* \text { GLCM } 23 \text { Mean } 8-2.776 * \text { GLCM } 23 \text { Corr } 5-4191.491
\end{gathered}
$$

- Estimation of tropical rainforest biomass/carbon based on very high resolution satellite data can be improved by (a) developing and applying forest stratum-specific models, and (b) including textural information in addition to spectral information.

- WorldView-2 data are a valuable data source for biomass estimation. In this study, the main asset of WorldView-2 proved to be the sensor's additional spectral bands and the spatial resolution of $2.0 \mathrm{~m}$. The main drawback of the sensor is the lack of a middle-infrared band. The panchromatic band with its very high spatial resolution of $0.5 \mathrm{~m}$ might provide important information regarding other forest parameters such as crown area, crown diameter, and DBH; however, this question was beyond the scope of this study and will have to be examined in the future. 
The next research steps will include analyzing the linkages between larger samples of tropical forest biomass data and satellite data with the same or similar spectral and spatial characteristics to confirm the present results and test the robustness of the developed models. Influences of varying acquisition and illumination geometries of other satellite scenes on the RMSE will have to be analyzed as well. Finally, future research will also focus on the assessment of carbon stock stored in secondary formations.

\section{Acknowledgments}

The author would like to thank DigitalGlobe for providing the WorldView-2 data at no charge. The author would also like to thank the team around Gabrielle Lalanirina Rajoelison: Harifidy Rakoto Ratsimba and Lovanirina Olivia Rakotondrasoa of École Supérieure des Sciences Agronomiques, Département des Eaux et Forêts, Université d'Antananarivo, who performed field work and laboratory analysis. Without their untiring efforts and hard work to establish the biomass and carbon forest inventory, this study would not have been possible.

\section{References}

1. UNEP-WCMC. The Linkages between Biodiversity and Climate Change Mitigation; UNEP-WCMC: London, UK, 2008. Available online: http://www.cbd.int/doc/meetings/cc/ ahteg-bdcc-02-02/official/ahteg-bdcc-02-02-05-en.pdf (accessed on 25 March 2012).

2. UNFCCC. Outcome of the Work of the Ad Hoc Working Group on Long-Term Cooperative Action under the Convention-Policy Approaches and Positive Incentives on Issues Relating to Reducing Emissions from Deforestation and Forest Degradation in Developing Countries; and the Role of Conservation, Sustainable Management of Forests and Enhancement of Forest Carbon Stocks in Developing Countries. In Proceedings of UNFCCC COP 16, Cancun, Mexico, 29 November-10 December 2010.

3. UNFCCC. Methodological Guidance for Activities Relating to Reducing Emissions from Deforestation and Forest Degradation and The role of Conservation, Sustainable Management of Forests and Enhancement of Forest Carbon Stocks in Developing Countries; Draft Decision/CP.15; Advanced unedited version, UNFCCC: Bonn, Germany 2009. Available online: http://unfccc.int/files/na/application/pdf/cop15_ddc_auv.pdf (accessed on 25 July 2011).

4. Ecoreserve. What is the UN-REDD Programme; Ecoreserve: San Francisco, CA, USA, 2010. Available online: http://www.ecoreserve.org/2010/06/02/what-is-the-un-redd-programmereducing-emissions-from-deforestation-and-forest-degradation-in-developing-countries/ (accessed on 20 February 2011).

5. $\mathrm{Lu}, \mathrm{D}$. The potential and challenge of remote sensing-based biomass estimation. Int. J. Remote Sens. 2006, 27, 1297-1328.

6. Dong, J.; Kaufmann, R.K.; Myneni, R.B.; Tucker, C.J.; Kauppi, P.E.; Liski, J.; Buermann, W.; Alexeyev, V.; Hughes, M.K. Remote sensing estimates of boreal and temperate forest carbon pools, sources, and sinks. Remote Sens. Environ. 2003, 84, 393-410.

7. Lu, D. Aboveground biomass estimation using Landsat TM data in the Brazilian Amazon. Int. J. Remote Sens. 2005, 26, 2509-2525. 
8. Sarker, L.R.; Nichol, J.E. Improved forest biomass estimates using ALOS AVNIR-2 texture indices. Remote Sens. Environ. 2011, 115, 968-977.

9. Nelson, R.F.; Kimes, D.S.; Salas, W.A.; Routhier, M. Secondary forest age and tropical forest biomass estimation using Thematic Mapper imagery. Bioscience 2000, 50, 419-431.

10. Fuchs, H.; Magdon, P.; Kleinn, C.; Flessa, H. Estimating aboveground carbon in a catchment of the Siberian forest tundra: Combining satellite imagery and field inventory. Remote Sens. Environ. 2009, 113, 518-531.

11. Boyd, D.S.; Danson, F.M. Satellite remote sensing of forest resources: Three decades of research development. Progr. Phys. Geogr. 2005, 29, 1-26.

12. Tuominen, S.; Pekkarinen, A. Performance of different spectral and textural aerial photograph features in multi-source forest inventory. Remote Sens. Environ. 2005, 94, 256-268.

13. Eckert, S.; Rakoto Ratsomba, H.; Rakotondrasoa, L.O.; Rajoelison, L.G.; Ehrensperger, A. Deforestation and forest degradation monitoring and assessment of biomass and carbon stock of lowland rainforest in the Analjirofo region, Madagascar. For. Ecol. Manage. 2010, 262, 19962007.

14. White, F. The Vegetation of Africa, a Descriptive Memoire to Accompany UNESCO/AETFAT Vegetation Map of Africa; UNESCO: Paris, France, 1983.

15. Humbert, H.; Cours-Darne, G. Carte Internationale du Tapis Végétal et des Conditions Écologiques; Travaux de la Section Scientifique et Technique, Institut Français: Pondichery, France, 1965; Volume 6, p. 162.

16. Humbert, H. La Destruction d'une Flore Insulaire par le Feu. Principaux Aspects de la végétation à Madagascar. In Mémoires de L'Académie Malgache, Fascicule V; Pitot, G., Ed.; Tananarive, Madagascar, 1927.

17. Rauh, W. Problems of Biological Conservation in Madagascar. In Plants and Islands; Bramweil, D., Ed.; Academic Press: London, UK, 1979; pp. 405-421.

18. Jolly, A.; Jolly, R. Malagasy Economics and Conservation: A Tragedy without Villains. In Key Environments: Madagascar; Jolly, A., Oberlé, P., Roland, R., Eds.; Pergamon Press: Oxford, UK, 1984; pp. 211-217.

19. Sussman, R.W.; Richard, A.F.; Ravelojaona, G. Madagascar: Current projects and problems in conservation. Primate Conserv. 1985, 5, 53-59.

20. Jenkins, M.D. Madagascar: An Environmental Profile; IUCN: Gland, Switzerland, 1987.

21. Valentine, H.T.; Tritton, L.M.; Furnival, G.M. Subsampling trees for biomass, volume, or mineral content. For. Sci. 1984, 30, 673-681.

22. Gregoire T.G.; Valentine H.T.; Furnival G.M. Sampling methods to estimate foliage and other characteristics of individual trees. Ecology 1995, 56, 1181-1194.

23. Chave, J.; Andalo, C.; Brown, S.; Cairns, M.A.; Chambers, J.Q.; Eamus, D.; Fölster, H.; Fromard, F.; Higuchi, N.; Kira, T.; et al. Tree allometry and improved estimation of carbon stocks and balance in tropical forests. Oecologia 2005, 145, 87-99.

24. Brown, S. Estimating Biomass and Biomass Change of Tropical Forests: A Primer; FAO Forestry Paper 134; FAO: Rome, Italy, 1997. 
25. Rajoelison, L.G. Méthodologie d'Analyse Sylvicole dans une Forêt Naturelle; Akon'ny Ala No. 8; Bulletin du Département des Eaux \& Forêts de l'Ecole Supérieure des Sciences Agronomiques; Université d'Antananarivo: Antananarivo, Madagascar 1992; pp. 9-19.

26. Rakotondrasoa, L.O. Etude du Stock de Carbone de la Forêt de Manompana: Nord Est de Madagascar; Mémoire de Diplômes d'Etudes Approfondies; Ecole Supérieure des Sciences Agronomiques, Département des Eaux et Forêts, Université d'Antananarivo: Antananarivo, Madagascar, 2009.

27. Rakoto Ratsimba, H.; Rajoelison, L.G.; Rakotondrasoa, L.O.; Eckert, S.; Hergarten, C.; Ehrensperger, A. Dégradation des Forêts et Stock de Carbone dans la Biomasse Epigée de la Forêt dens Humide de Manompana: Nord Est de Madagascar. Presented at the International Scientific Conference on Technologies for Development, Lausanne, Switzerland, 8-10 February 2010.

28. Houghton, J.T., Meira Filho, L.G., Lim, B., Treanton, K., Mamaty, I., Bonduki, Y., Griggs, D.J., Callender, B.A., Eds. IPCC Guidelines for National Greenhouse Gas Inventories Volume 3; Greenhouse Gas Inventory Reference Manual (Revised ed.); IPCC/UK Meteorological Office: Bracknell, UK, 1996.

29. DigitalGlobe. WorldView-2 Datasheet; DigitalGlobe: Longmont, CO, USA, 2010. Available online: http://dgl.us.neolane.net/res/dgl/survey/_8bandchallenge_resources.jsp?deliveryId=\&id= (accessed on 28 July 2011).

30. DigitalGlobe. Radiometric Use of WorldView-2 Imagery; Technical Note; DigitalGlobe: Longmont, CO, USA, 2010. Available online: http://dgl.us.neolane.net/res/dgl/ survey/_8bandchallenge.jsp. (accessed on 16 March 2011).

31. Richter, R. Atmospheric/Topographic Correction for Satellite Imagery (ATCOR-2/3 User Guide 7.0); DLR-IB 565-01/09; DLR: Wessling, Germany, 2009.

32. Lu, D.; Mausel, P.; Brondizio, E.; Moran, E. Relationships between forest stand parameters and Landsat TM spectral responses in the Brazilian Amazon Basin. For. Ecol. Manage. 2004, 198, 149-167.

33. Eckert, S. A Contribution to Sustainable Forest Management in Patagonia: Object-Oriented Classification and Forest Parameter Extraction based on ASTER and Landsat ETM+ Data. Ph.D. Thesis, University of Zurich, Zurich, Switzerland, 2005.

34. Kaufman, YJ.; Tanré, D. Atmospherically resistant vegetation index (ARVI) for EOS-MODIS. IEEE Trans. Geosci. Remote Sens. 1992, 30, 261-270.

35. Huete, A.; Didan, K.; Miura, T.; Rodriguez, E.P.; Gao, X.; Ferreira, L.G. Overview of the radiometric and biophysical performance of the MODIS vegetation indices. Remote Sens. Environ. 2002, 83, 195-213.

36. Crippen, R.E. Calculating the vegetation index faster. Remote Sens. Environ. 1990, 34, 71-73.

37. Rouse, J.W.; Haas, R.H.; Schell, J.A.; Deering, D.W. Monitoring Vegetation Systems in the Great Plains with ERTS. In Third ERTS Symposium, NASA SP-351; NASA: Washington, DC, USA, 1973; Volume 1, pp. 309-317.

38. Rondeaux, G.; Steven, M.; Baret, F. Optimation of soil-adjusted vegetation indices. Remote Sens. Environ. 1996, 55, 95-107. 
39. Richards, J.A. Remote Sensing Digital Image Analysis: An Introduction; Springer-Verlag: Berlin, Germany, 1999; p. 240.

40. Jordan, C.F. Derivation of leaf area index from quality of light on the floor. Ecology 1969, 50, 663-666.

41. Kanemasu, E.T. Seasonal canopy reflectance patterns of wheat, sorghum, and soybean. Remote Sens. Environ. 1974, 3, 43-47.

42. Haralick, R.M.; Shanmugan, K.; Dinstein, I. Textural features for image classification. IEEE Trans. Syst. Man Cybern. 1973, 3, 610-621.

43. Huete, A.R.; Liu, H.Q.; Van Leeuwen, W.J.D. The Use of Vegetation Indices in Forested Regions: Issues of Linearity and Saturation. In Proceedings of 1997 IEEE International Geoscience and Remote Sensing Symposium, Noordwijk, The Nederlands, 3-8 August 1997; pp. 1966-1968.

44. Leboeuf, A.; Beaudoin, A.; Forunier, R.A.; Guindon, L.; Luther, J.E.; Lambert, M.C. A shadow fraction method for mapping biomass of northern boreal black spruce forests using Quickbird imagery. Remote Sens. Environ. 2007, 110, 488-500.

45. Steininger, M.K. Satellite estimation of tropical secondary forest above-ground biomass: Data from Brazil and Bolivia. Int. J. Remote Sens. 2000, 21, 1139-1157.

46. Thenkabail, P.S.; Enclona, E.A.; Ashton, M.S.; Legg, C.; Jean De Dieu, M. Hyperion, IKONOS, ALI, and ETM+ sensors in the study of African rainforests. Remote Sens. Environ. 2004, 90, 23-43.

47. Castillo-Santiago, M.A.; Ricker, M.; De Jong, B.H.J. Estimation of tropical forest structure from SPOT-5 satellite images. Int. J. Remote Sens. 2010, 31, 2767-2782.

48. Foster, J.R.; Kingdon, C.C.; Townsend, P.A. Predicting Tropical Forest Carbon from EO-1 Hyperspectral Imagery in Noel Kempff Mercado National Park, Bolivia. In Proceedings of 2002 IEEE International Geoscience and Remote Sensing Symposium, IGARSS '02, Toronto, ON, Canada, 24-28 June 2002; Volume 6, pp. 3108-3110.

(C) 2012 by the authors; licensee MDPI, Basel, Switzerland. This article is an open access article distributed under the terms and conditions of the Creative Commons Attribution license (http://creativecommons.org/licenses/by/3.0/). 